Original Research Paper

\title{
Bamboo Lightweight Shear Walls: Modeling and Identification of Sheathing-to-Framing Connections for Seismic Response Analysis
}

\author{
${ }^{1}$ Giorgia Di Gangi, ${ }^{2}$ Cristoforo Demartino and ${ }^{1}$ Giuseppe Quaranta \\ ${ }^{1}$ Department of Structural and Geotechnical Engineering, Sapienza University of Rome, Rome, Italy \\ ${ }^{2}$ University of Illinois at Urbana Champaign Institute, Zhejiang University, Haining, Zhejiang, China
}

\author{
Article history \\ Received: 14-03-2020 \\ Revised: 11-04-2020 \\ Accepted: 03-06-2020 \\ Corresponding Author: \\ Giuseppe Quaranta \\ Department of Structural and \\ Geotechnical Engineering, \\ Sapienza University of Rome, \\ Rome, Italy \\ Email: giuseppe.quaranta@uniroma1.it
}

\begin{abstract}
The need for enhancing the sustainability of civil constructions has originated an increasing interest in the use of engineered bamboo-based products within the building sector. Nonetheless, while the static response of bamboo-made structures has been largely investigated, experimental and numerical researches concerning the response under dynamic loads are limited. Therefore, the present work deals with the assessment of the seismic behavior of modern bamboo lightweight shear walls, with focus on the energy dissipation ensured by sheathing-to-framing connections. Initially, a short discussion about architectural, sustainability and manufacturing issues related to the use of bamboo in modern civil constructions is provided. Then, the experimental cyclic response of fasteners employed within glued laminated bamboo (glubam) shear walls is simulated by using a suitable phenomenological model whose parameters are identified through a soft computing-based numerical technique. A parametric finite element model developed within OpenSees is thus employed to assess the global seismic response of the wall. A comparison between the response of glubam- and timber-based shear walls is finally provided. This highlights that the main parameter dictating their global behavior is the local non-linear behavior of the single fastener when the crosssection size of the framing elements allows the full exploitation of its capacity and plastic deformation. The numerical simulations well agree with the main evidence carried out from the available experimental data. Particularly, it is found that glubam lightweight shear walls usually exhibit larger capacity and reduced ductility with respect to equivalent timber walls.
\end{abstract}

Keywords: Bamboo, Finite Element Model, Glubam, OpenSees, Parametric Identification, Shear Wall

\section{Introduction}

According to the Energy Policy Act of 2005, Public Law 109-058 (USC, 2005), the main function of the buildings is to host communities and their activities while ensuring energy efficiency, durability, suitable performance throughout the entire life-cycle and satisfactory occupant productivity. Hence, nowadays designers are more and more often requested to take into proper account, both, environmental and structural issues within their projects. This, in turn, stimulates the search for sustainable solutions able to fulfill safety issues imposed by modern design codes with respect to pertinent limit states.
The need of designing sustainable buildings and saving as much natural resources as possible is rapidly changing the way by which the constructions are conceived (Kibert, 2016) through the implementation of green building concepts and solutions. In the United States, for example, the concept of Net Zero Energy (NZE) plays a central role within a wide national program called "Architecture 2030 Challenge". According to such a program, buildings have to generate as much energy as possible from renewable sources, while reducing the greenhouse gas emission during the construction process or their major renovations (climate-neutral operations). European Countries are also committed to achieve a similar result. 
Among the strategies that can be adopted to make the building sector more sustainable, the selection of construction materials deserves special attention. In this regards, green materials (i.e., natural materials or recycled, recyclable and reusable materials) can be a viable way to reduce the negative environmental impacts of the buildings, but it is always important to keep in mind that they must also ensure the fulfillment of satisfactory performance for structural applications in compliance with the requirements imposed by modern design codes.

Within this framework, the use of timber species in the building sector is especially attractive because of the reduced embodied energy needed for the acquisition of raw material, its production, processing, manufacturing and transportation as well as the reduced $\mathrm{CO}_{2}$ emission throughout the whole life-cycle and the rapid regeneration. Compared to hardwood, bamboo is considered to be one of the most sustainable species and its mechanical properties are attractive for modern architectural applications.

Bamboo is a grass plant used since long time to build basic habitats as well as complex structures. The most common bamboos for constructions in tropical zones are Bambusa, Chusquea, Dendrocalamus, Gigantochload and Guadua whereas the group of Phyllostachys is mainly used in temperate zones. Bamboo plants have several positive environmental impacts, e.g., biomass production, reduction of soil erosion because of the dense network of roots that anchors earth and helps to lessen erosion due to rain and flooding, water retention, regulation of hydraulic flow (because of the retaining water in its stem) and temperature reduction due to its leaves. Moreover, because of its rapid growth, bamboo can take in more $\mathrm{CO}_{2}$ than a tree while producing oxygen (Ghavami, 2008), which is relevant for international greenhouse gas emission allowance trading.

In the past, bamboo has been used mostly in rural zones of warm humid climate such as Indonesia and India, initially for the construction of scaffolding (Minke, 2016). Several traditional construction systems based on the use of the round (unprocessed) bamboo have been also developed worldwide for structural applications. In Latin American countries, for instance, the technologies in use have been classified into various systems like Bahareque, Quincha and others, as listed and described accurately by Paudel (2008). Although bamboo has very good mechanical properties on average, its use in natural form as a structural material is limited by its non-uniform behavior (Li et al., 2012; Xiao et al., 2014a). This is the main reason for which engineered bamboo-based products have been developed in the last decades. For instance, Laminated Bamboo Lumber (LBL) based products have been developed in South America and China (Mahdavi et al., 2010) for structural applications, which is produced gluing slender strips obtained through a splitter machine.
As reported in (Jayanetti and Follett, 2008), nowadays bamboo is more and more often employed for both structural and non-structural elements, except fireplaces and chimneys, due to its flammability. Apart from building structures, the use of bamboo has been also extended to bridges, generally for trestle constructions with limited span for carrying light traffic only (mostly pedestrian). The use of bamboo as concrete reinforcement is also rather common in constructions (Ashby, 1992; Wegst et al., 1993). The way of using bamboo in buildings is similar to that in use for timber frame constructions, i.e., floor, wall and roof elements are interconnected and often dependent on each other for the overall capacity and stability. It should be highlighted, however, that bamboo-based products can be rather expensive, with a cost up to four times with respect to similar timber-based products, due to the not industrialized manufacturing procedure (Xiao et al., 2013).

Among the modern bamboo-based products for advanced sustainable building solutions, glubam (Xiao et al., 2014b) is one of the most promising. This product consists of bamboo layers cold-glued with different orientations according to structural and architectural requirements of the element they made. Typically, glubambased lightweight shear walls are employed within one- or two-storeys platform framed constructions and are the main structural elements resisting to lateral forces due to, for instance, seismic or wind loads. As for common light-frame timber shear walls, glubam lightweight shear walls consist of vertical studs and horizontal plates (Wang et al., 2018) assembled in a hinged frame (Fig. 1). Sheathing panels made of thick strip ply-bamboo boards are considered herein, according to the experimental layout adopted by Wang et al. (2019). They are connected to the foundation (usually made of concrete or masonry blocks) or to the lower story walls through the floor by using anchoring devices typically made of steel bolts. The roof system (usually made of prefabricated trusses) is attached to the top beam of the shear wall by using metal connections.

Existing studies (Wang et al., 2017) indicate that glubam lightweight shear walls have higher strength but lower ductility (i.e., ultimate-to-yielding displacement ratio) with respect to light-frame timber shear walls. In order to shed a light on this aspect, an extensive comparative analysis on the in-plane seismic performance of glubam lightweight and timber shear walls is carried out in the present work, with special attention on the role of the sheathing-to-framing connections. To this end, the Finite Element (FE) parametric model developed by Di Gangi et al. (2020) within the open-source software OpenSees (McKenna and Fenves, 2001; Moghadam, 2017) has been exploited to carry out a rather large sensitivity analysis. The final results obtained for glubam lightweight shear walls are useful to assess the influence of the geometric input parameters on the global seismic performance as well as to evaluate their behavior with respect to timber light-frame shear walls. 


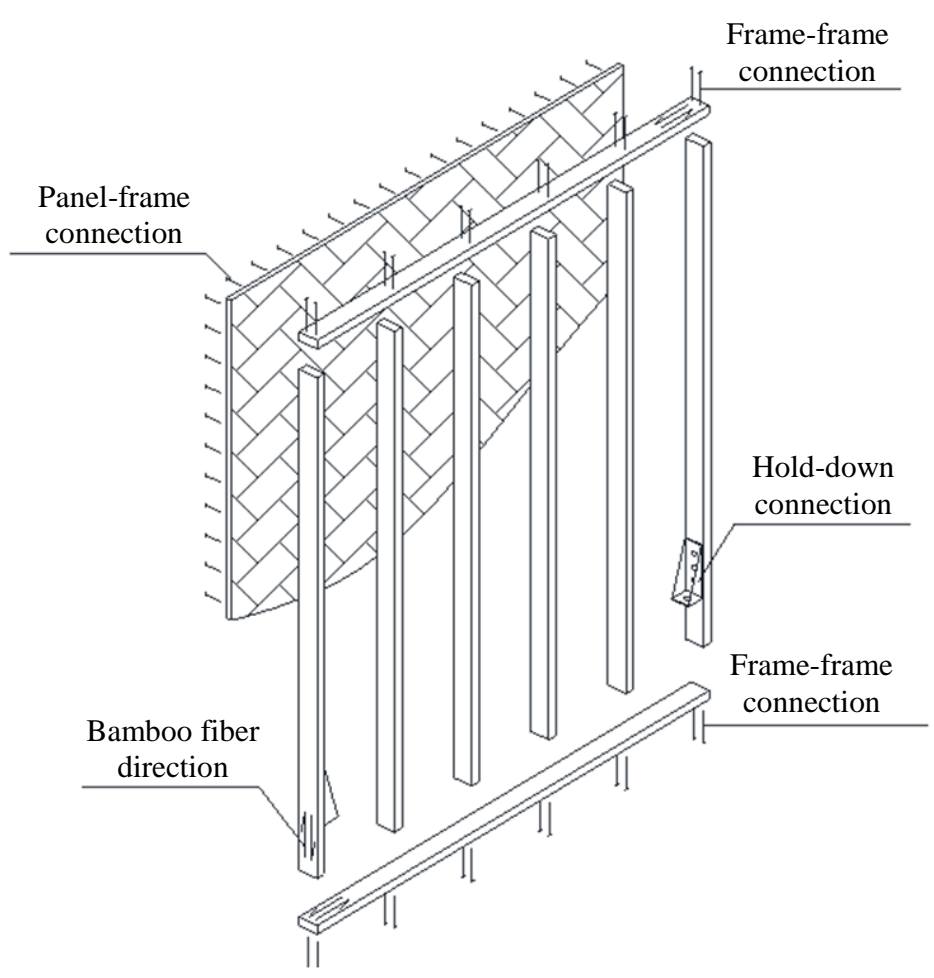

Fig. 1: Glubam lightweight shear walls, with details of the connections

\section{Numerical Modeling}

\section{Finite Element Model of the Glubam Shear Wall}

The parametric FE model developed by Di Gangi et al. (2020) has been exploited to study the response of glubam lightweight shear walls under in-plane cyclic loading, including the energy dissipation ensured by sheathing-to-framing connections. The elastic modulus of glubam is assumed $E=10.3 \mathrm{GPa}(\mathrm{Li}, 2015)$. Sheathing-to-framing connections are made of $50 \mathrm{~mm}$ HS nails (diameter $3.36 \mathrm{~mm} / 0.13 \mathrm{in}$., length $50.05 \mathrm{~mm} / 1.97$ in.), whose experimental cyclic response (Fig. 2) has been obtained by Wang et al. (2019). The Seismic Analysis of Wood Structures (SAWS) model (Foschi, 1974; Dolan, 1989; Folz and Filiatrault, 2001), available within the OpenSees library, has been employed to simulate the hysteretic response of this fastener under cyclic loading.

Experimental data for the $50 \mathrm{~mm}$ HS connection in use within bamboo lightweight shear walls have been considered in the present study because the corresponding softening-type response and ultimate displacement are close, to some extent, to those measured for the ring nail $\Phi 2.8 / 70$ by Gattesco and Boem (2016), which is in use within timber light-frame shear walls. This choice, in turn, allows a fairly unbiased numerical comparative assessment of bamboo and timber shear walls performance taking into account the different construction practices, after experimental data-based parametric identification of the nonlinear dynamic model ruling the hysteretic response of the corresponding fastener connections.

Following the approach most commonly in use within the current literature, it is assumed that holddown and angle-bracket connections are designed with over strength and thus their contribution to the overall nonlinear behavior can be deemed negligible. This is because the nonlinear in-plane cyclic global behavior of the shear wall rests on the hysteretic response of the sheathing-to-framing connections (Tuomi and McCutcheon, 1978; Gupta and Kuo, 1985; 1987; Gutkowski and Castillo, 1988; White and Dolan, 1995). No vertical load was applied and P- $\Delta$ effect was neglected during the numerical analysis, since it has a very limited influence on the displacements range obtained in the following numerical investigations (Jayamon et al., 2016).

\section{Parametric Identification of the Fastener Model}

The parametric identification of the SAWS model, intended to simulate the hysteretic response of the 50 mm HS nail, has been carried out using the differential evolution algorithm (Ma et al., 2006; Quaranta et al., $2010 ; 2020)$. Such an algorithm is employed to look for the minimum of the following objective function:

$$
f(\boldsymbol{\theta})=\frac{1}{S \cdot \operatorname{var}\left(\mathbf{F}_{\text {ex }}\right)}\left(\mathbf{F}_{\text {num }}-\mathbf{F}_{\text {ex }}\right)^{T}\left(\mathbf{F}_{\text {num }}-\mathbf{F}_{\text {ex }}\right)
$$

where: 


$$
\boldsymbol{\theta}=\left\{F_{o}, F_{1}, D_{u}, S_{o}, R_{1}, R_{2}, R_{3}, R_{4}, \alpha, \beta\right\}
$$

is the vector of the SAWS model parameters to be identified (Fig. 3), $\mathbf{F}_{\text {num }}$ and $\mathbf{F}_{\mathbf{e x}}$ are predicted and experimental force values, respectively, $S$ is the total number of experimental data points whereas $\operatorname{var}\left(\mathbf{F}_{\mathbf{e x}}\right)$ is the variance of the measured response. The estimated parameters (together with lower and upper bounds in the optimization problem) are listed in Table 1. Figure 4 demonstrates a good agreement between the experimental and identified force-displacement curves of the single $50 \mathrm{~mm}$ HS nail.

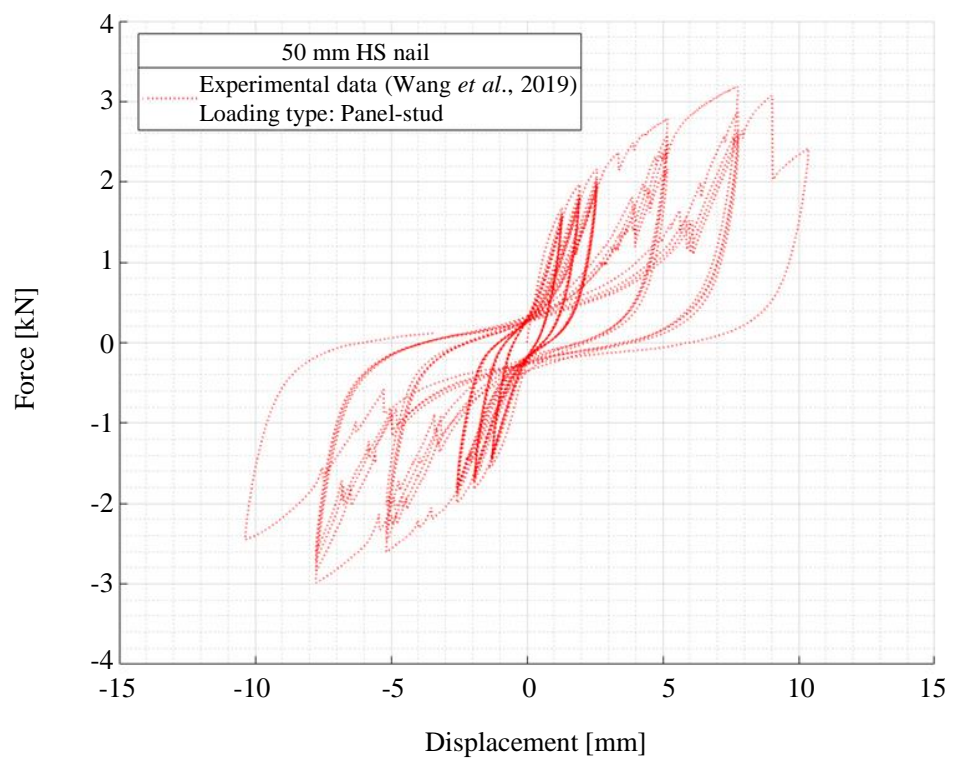

Fig. 2: Experimental response of a single $50 \mathrm{~mm}$ HS nail loaded in the panel-stud direction (Wang et al., 2019)

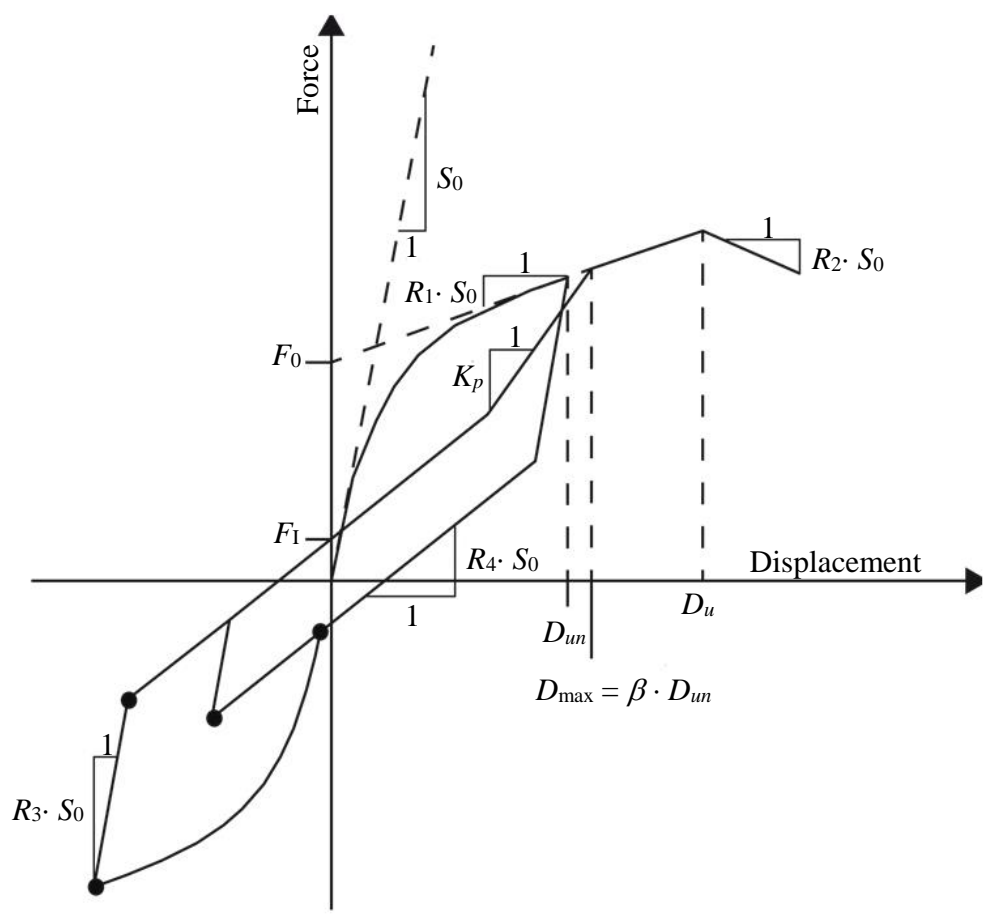

Fig. 3: Force-displacement cycle of the SAWS material model parameters. Here, $D_{u n}$ is the last unloading displacement (which controls the strength degradation) and $K_{p}=S_{0}\left[\left(F_{0} / S_{0}\right) / D_{\max }\right]^{\alpha}$ (Di Gangi et al., 2020) 


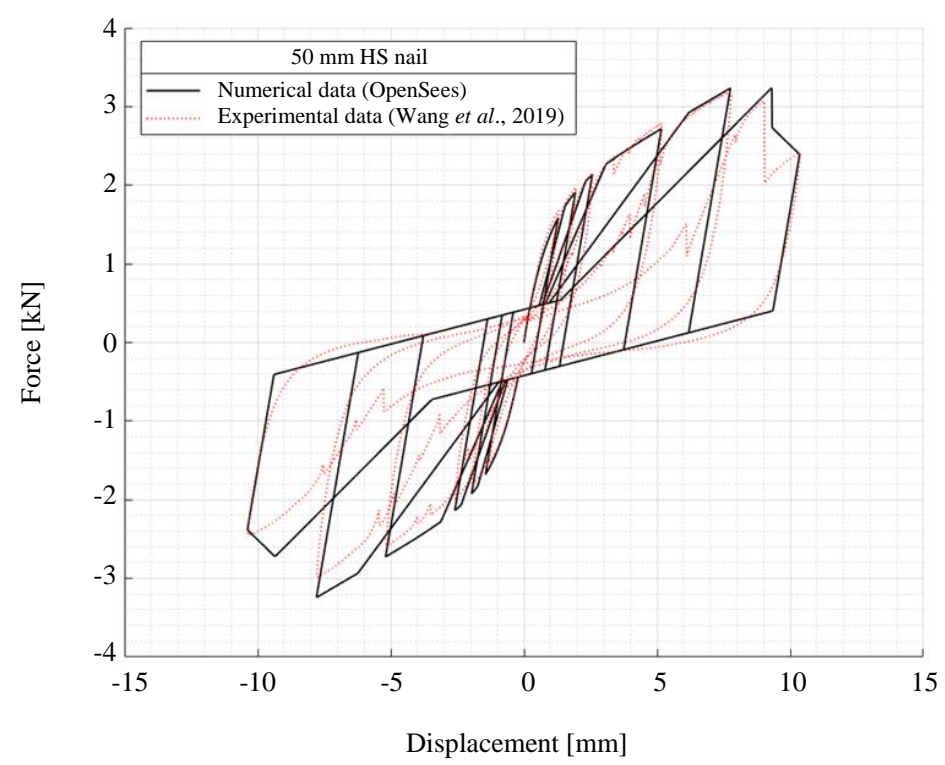

Fig. 4: Identification of the SAWS mechanical model for the sheathing-to-framing connections: comparison between experimental data by Wang et al. (2019) and numerical predictions

Table 1: Identified SAWS model parameters by using the experimental data in (Wang et al., 2019) for a 50 mm HS nail. Lower and upper bounds of the search space are also listed

\begin{tabular}{llll}
\hline & Lower bound & Upper bound & Identified \\
\hline$F_{0}[\mathrm{kN}]$ & 1.44 & 2.16 & 1.7 \\
$F_{\mathrm{I}}[\mathrm{kN}]$ & 0.336 & 0.504 & 0.42 \\
$D_{u}[\mathrm{~mm}]$ & 6.224 & 9.336 & 7.75 \\
$S_{0}[\mathrm{kN} / \mathrm{mm}]$ & 1.56 & 2.34 & 2.2 \\
$R_{1}[-]$ & 0.072 & 0.108 & 0.09 \\
$R_{2}[-]$ & -0.019 & -0.288 & -0.15 \\
$R_{3}[-]$ & 0.072 & 0.108 & 0.9 \\
$R_{4}[-]$ & 0.032 & 0.048 & 0.04 \\
$\alpha[-]$ & 0.6 & 0.9 & 0.75 \\
$\beta[-]$ & 0.96 & 1.44 & 1.2 \\
\hline
\end{tabular}

\section{Numerical Assessment of the Response}

\section{Sensitivity Analysis}

An extensive sensitivity analysis has been carried out to investigate the seismic performance of glubam lightweight shear walls in terms of racking load-carrying capacity and energy dissipation. The numerical assessment has been performed by imposing a horizontal cyclic loading (in displacement-controlled conditions) to the top plate of the wall and changing one parameter at a time, starting from the usual configuration of a typical glubam lightweight shear wall with conventional $38 \times 89 \mathrm{~mm}^{2}$ framing elements cross-sections (Wang et al., 2019).

The global displacement is increased until the failure criterion is reached and then it is reversed, thus obtaining a symmetric loop. The local failure of the first fastener identifies the reversing point (most of the times, it is the fastener placed at the bottom corner of the wall). This displacement value denotes the collapse limit state of the glubam lightweight shear wall and is set equal to $10.37 \mathrm{~mm}$, which corresponds to a strength reduction of the fastener equal to $27 \%$ (Fig. 2). Once the first fastener fails, all the adjacent fasteners fail sequentially as well. The life safety limit state can also be defined and it corresponds to the racking load-carrying capacity of the wall.

It has been observed numerically that a life safety limit state is reached when almost all of the boundary fasteners exceed the displacement $D_{u}$ corresponding to their peak force, which is equal to $7.75 \mathrm{~mm}$ (Fig. 2).

For a comparative assessment, light-frame timber shear walls are also analyzed. The reference configuration of the light-frame timber shear wall has framing elements with a cross-section size equal to $120 \times 160 \mathrm{~mm}^{2}$ for horizontal plates and $140 \times 160 \mathrm{~mm}^{2}$ for vertical studs.

Note that the difference in the geometries of timber- and glubam-based reference wall assemblages takes into account the real construction practices and the need to perform an unbiased comparative assessment of the two systems.

In passing, it is remarked that the reference lightframe timber shear wall model has been validated in (Di Gangi et al., 2020) using the experimental data provided by Gattesto and Boem (2016) for the selected wall specimen (PLS8). As regards the sheathing-toframing connections for light-frame timber shear walls, the hysteretic behavior of the ring nail $\Phi 2.8 / 70$ has been simulated through the SAWS mechanical model and the corresponding parameters have been already calibrated by Di Gangi et al. (2020) using the experimental data provided by Gattesco and Boem (2016). 
The mechanical properties of the timber refer to that of red spruce wood species with strength class C24, in accordance with Table 1 of EN 338:2003 (BSI, 2016). Specifically, wood mean characteristic value of modulus of elasticity parallel to grain is $E=11 \mathrm{GPa}$.

The following parameters are varied to carry out the sensitivity analysis: (i) the height-to-width ratio of the wall, (ii) the horizontal and vertical fasteners spacing, (iii) the number of vertical studs, (iv) the cross-section size of the framing elements. Final results are shown in Fig. 5. Following (Di Gangi et al., 2020), the considered values of the height-to-width ratio are $0.7,1$ and 1.4, where the height is kept constant (equal to $2.6 \mathrm{~m}$ ). Therefore, both squat and slender walls are considered. Horizontal and vertical fasteners spacing values are equal to 50,75 and $100 \mathrm{~mm}$. The number of vertical studs is taken equal to 3,4 or 5 . Framing elements with cross-sections equal to $38 \times 8938 \times 140$ and $140 \times 160 \mathrm{~mm}^{2}$ are assumed.

It can be inferred from Fig. 5a to $5 \mathrm{c}$ that real glubam lightweight shear walls have a larger capacity than lightframe timber shear walls, whereas their ductility (i.e., ultimate-to-yielding displacement ratio, where the latter corresponds to the racking load-carrying capacity of the wall) is rather limited, in agreement with experimentalbased evidence carried out by Wang et al. (2019).

In this regard, it is interesting to point out in Fig. 5a, $5 b, 5 c$ that glubam shear walls exhibit a larger loadcarrying capacity even though the cross-section size of their framing elements is smaller than those of timber light-frame shear walls and the similar elastic modulus value of the materials. This is mainly attributable to the higher load capacity of the fastener in glubam shear walls than the one in timber light-frame shear walls (in fact, the capacity of the $50 \mathrm{~mm}$ HS nail is twice the capacity of the ring nail $\Phi 2.8 / 70$ ). Such an evidence, in turn, highlights that the racking load-carrying capacity is mainly dictated by the capacity of the sheathing-toframing connections, if the size of the framing elements is large enough to allow the full exploitation of the single fastener capacity. Also note that considering the same layout with the largest cross-section size of the framing elements for both glubam and timber walls, the local capacity ratio between the ring nail $\Phi 2.8 / 70$ and the 50 $\mathrm{mm}$ HS nail is reflected almost unchanged into the global capacity of the wall. Moreover, for glubam shear walls, the configuration with the largest cross-section size of the framing elements is the only one that shows a softening behavior after the peak strength (Fig. 5d), because the capacity of the single fastener is fully exploited in such a layout. The corresponding global racking capacity results two times the one obtained with the smallest cross-section size of the framing elements.

On the other hand, the limited ductility observed in Fig. 5a to $5 \mathrm{c}$ for glubam shear walls can be attributable to the smaller cross-section size of their framing elements. In fact, the kinematic compatibility conditions between the shear-type behavior of the frame and that of the sheathing panel (which also rigidly rotates with respect to the frame) is crucial for the plastic deformation of the fasteners and affect both racking capacity and amount of energy dissipated during the global deformation of the wall.

As regards Fig. 5d, it is pointed out that the larger the cross-section size of the framing elements, the larger the plastic deformation of the fasteners and, consequently, the higher amount of dissipated energy and ductility. Considering the same layout for both glubam and timber walls, it is evident that the latter can generate larger plastic deformations in the employed fastener than the former, thus exhibiting a higher amount of dissipated energy, as illustrated in Fig. 5d.

The cross-section size of the framing elements is also crucial in determining the ultimate displacement of the walls. The smaller the cross-section size of the framing elements, the lower the global stiffness of the wall, see Fig. 5d. Although the ultimate displacement of the 50 $\mathrm{mm}$ HS nail is only $22 \%$ higher than the one of the ring nail $\Phi 2.8 / 70$, the global ultimate displacement of a glubam lightweight shear wall can be up to $63 \%$ higher than the one reached by a timber light-frame shear wall, see the response for the lowest height-to-width ratio in Fig. 5a. It is also worth highlighting that the wider the sheathing panel, the lower the displacement at the ultimate load (He et al., 1999).

Finally, it is worth noticing that the value of the displacement at the ultimate load in glubam shear walls is about $37-38 \%$ higher than the one reached by timber light-frame shear walls for almost the rest of the wall configurations considered herein.

\section{Assessment of Racking Capacity and Equivalent Viscous Damping}

The force-displacement curves obtained for the collapse limit state are considered in order to estimate numerically the equivalent viscous damping for glubam shear walls and to provide a comparison with the performance of light-frame timber shear walls.

The total equivalent viscous damping $\xi_{\text {tot }}$ is computed according to Chopra (1995), assuming an inherent viscous damping $\xi_{0.05}$ equal to $5 \%$. It reads:

$\xi_{\text {tot }}=\xi_{0.05}+\frac{E_{D}}{4 \pi E_{S 0}}$,

where:

$\xi_{e q}=E_{D} / 4 \pi E_{S 0}$

is the equivalent viscous damping computed as the ratio between the energy dissipated in a single cycle $E_{D}$ and the elastic strain energy in a half cycle $E_{S O}$. 


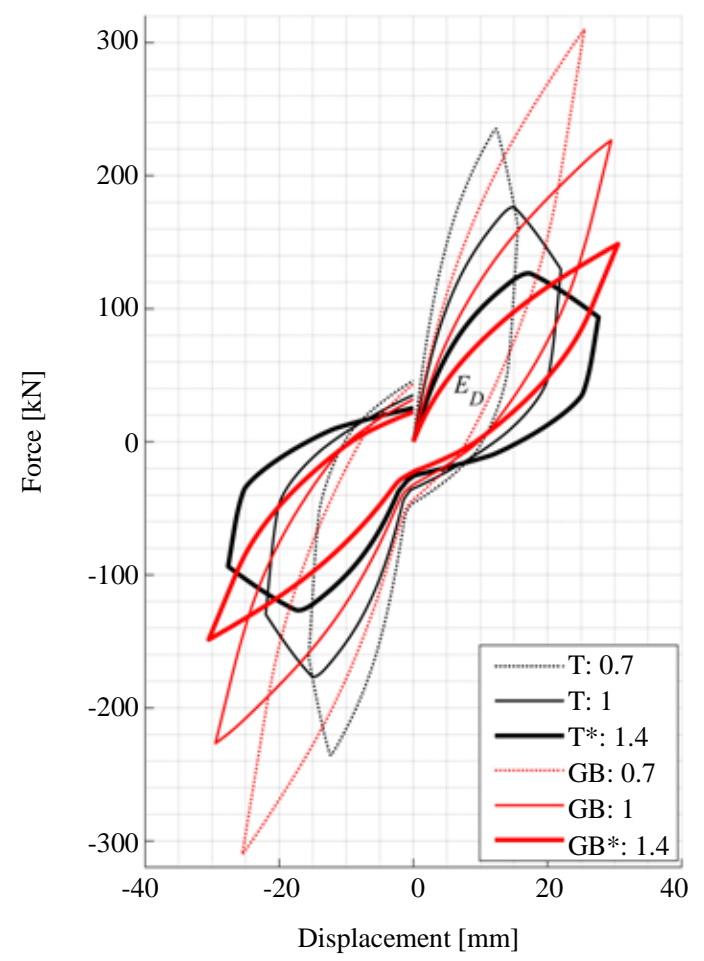

(a)

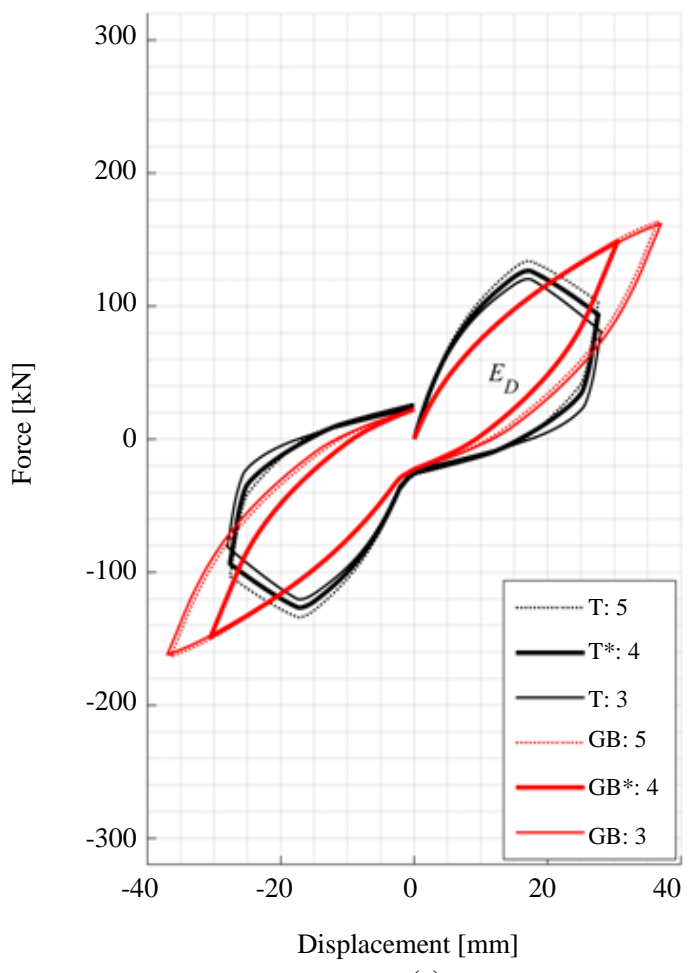

(c)

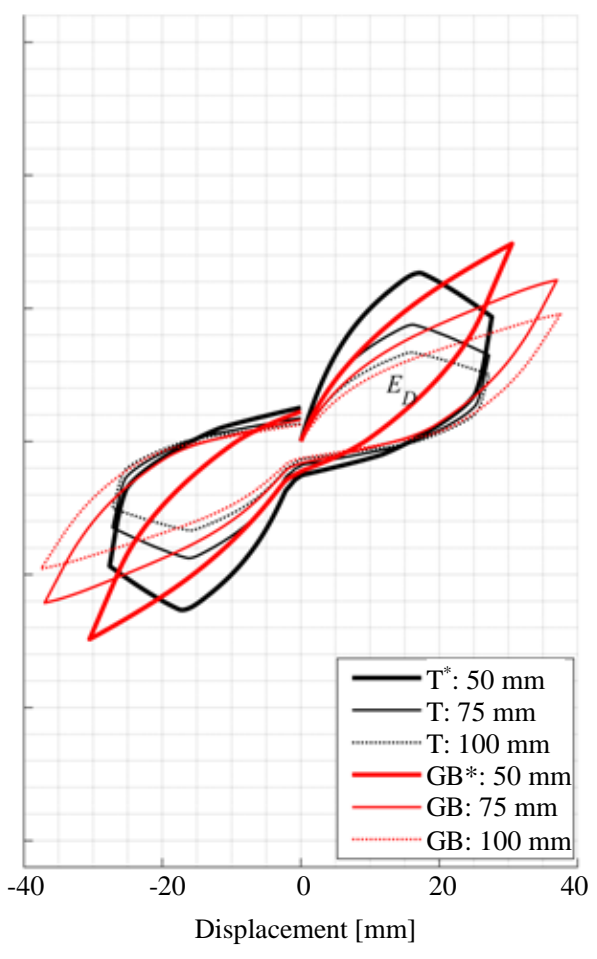

(b)

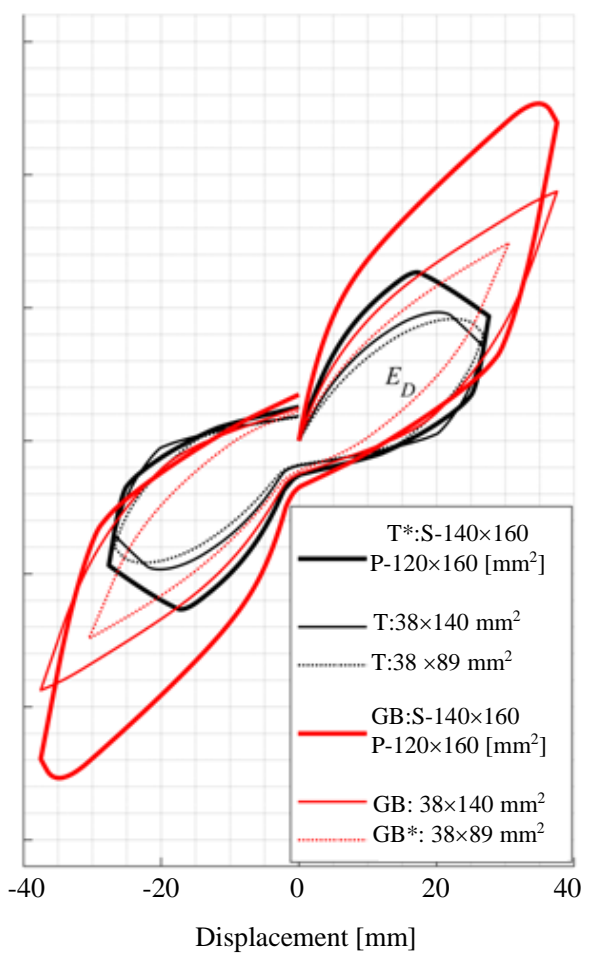

(d)

Fig. 5: Influence of (a) height-to-width ratio, (b) horizontal and vertical fasteners spacing, (c) number of vertical studs and (d) framing elements cross-section size on timber ("T", black lines) and glubam ("GB", red lines) lightweight shear walls (herein, "S" stands for studs cross-section and "P" stands for plates cross-section). The reference wall configuration is marked with an asterisk 
The damping correction factor $\eta$ in use within the Capacity Spectrum Method, is strictly correlated to the value of the total equivalent viscous damping and is computed as follows (CEN, 2004a):

$$
\eta=\sqrt{\frac{10}{5+\xi_{\text {tot }}}} .
$$

The values of racking capacity and total equivalent viscous damping are provided in Fig. 6 and 7 , respectively. It is evident that the total number of fasteners strongly affects the global nonlinear response of the wall.

Specifically, walls with a lower aspect ratio are characterized by higher racking capacity (Fig. 7) because this corresponds to a larger number of fasteners. This, however, does not affect the amount of dissipated energy (Fig. 6), mainly because a larger number of fasteners reduces their own plastic deformations.

The number of fasteners also increases by reducing their relative spacing. Once again, this does not influence the amount of dissipated energy whereas it affects the racking capacity of the wall, in line with the guidelines provided by the Eurocode 5 (CEN, 2004b, eq. 9.21)
The cross-section size of framing elements has effects on, both, dissipated energy and racking capacity, as it has been pointed out previously. In fact, the larger cross-section size of the framing elements allows the full exploitation of the plastic deformation of the fasteners and, consequently, the higher amount of ductility and dissipated energy, as shown in Fig. 6. It is also observed, however, that the racking capacity of glubam shear walls is much more sensitive to this parameter with respect to timber-based shear walls. This evidence is also related to the different constitutive law of the single fastener considered herein for glubam shear walls, which is characterized by higher capacity.

Moreover, it is evident that the number of studs has almost null effects on dissipated energy and racking capacity, regardless of the material employed for the shear wall. In fact, they are introduced to avoid buckling phenomena in the sheathing panels, as highlighted by Källsner and Girhammar (2009).

Finally, due to the reduced size assumed by the forcedisplacement envelopes of glubam shear walls, their total amount of dissipated energy is always lower than the one provided by timber light-frame shear walls. This can be ascribed to the constitutive law of a single fastener. In fact, its damage occurs before the fully exploitation of its plastic deformation.

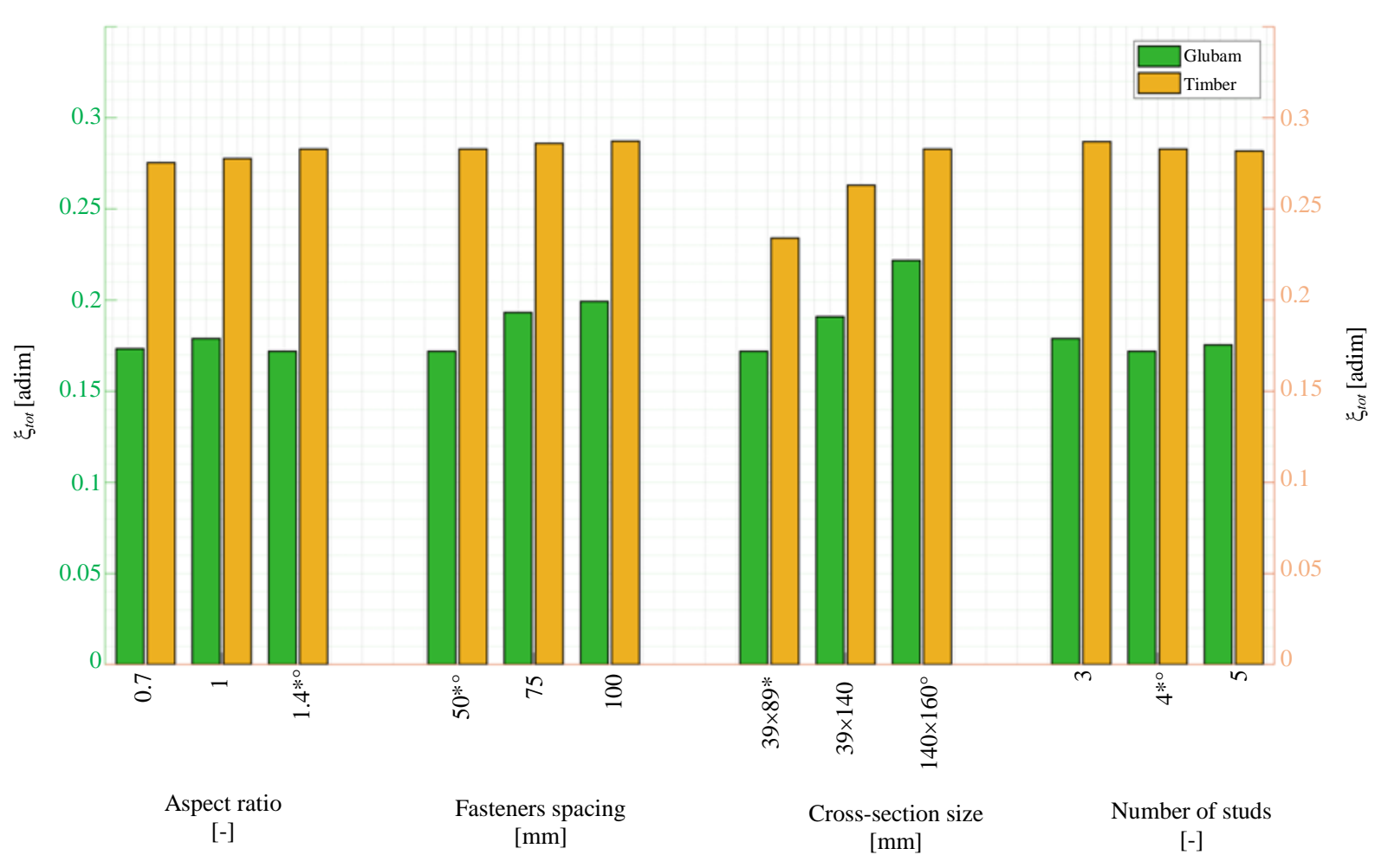

Fig. 6: Total equivalent viscous damping for collapse limit state condition for timber and glubam walls by varying the input parameters with respect to the reference wall configuration (the reference configuration for glubam walls is marked with an asterisk, whereas a circle is used for timber walls) 


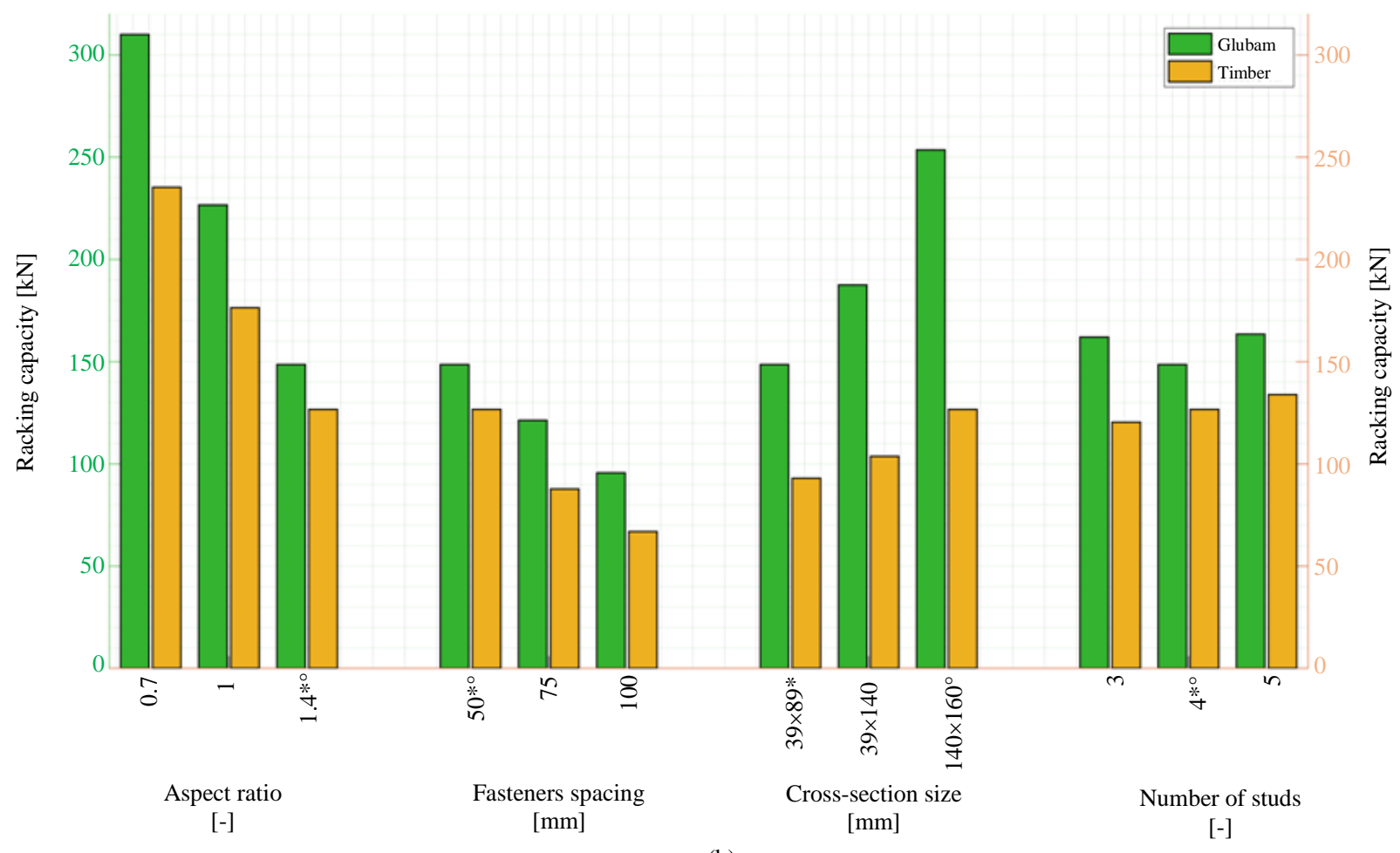

(b)

Fig. 7: Racking capacity for timber and glubam walls by varying the input parameters with respect to the reference wall configuration (the reference configuration for glubam walls is marked with an asterisk, whereas a circle is used for timber walls)

\section{Conclusion}

A comparison between the seismic performance of glubam- and timber-based lightweight shear walls has been presented in this work, by focusing the attention on the energy dissipation ensured by the sheathing-toframing connections under in-plane seismic loads. To this end, a parametric FE model implemented into the OpenSees platform has been used and the parameters of the numerical model employed to simulate the hysteretic behavior of the fasteners are identified by using recent experimental data.

In general, the constitutive law of a single fastener, the total number of fasteners employed within the layout and the cross-section size of the framing elements are the parameters that mainly affect the walls response. Although the unbiased comparative assessment between glubam and timber shear walls is made difficult by the different construction practices, the following general conclusions can be drawn.

In agreement with the available experimental data, numerical simulations reported herein confirm that glubam lightweight shear walls usually exhibit larger capacity and limited ductility with respect to timber walls.
Specifically, the racking load-carrying capacity largely depends on the capacity of the sheathing-toframing connections under the assumption that the framing elements size is large enough to allow the full exploitation of the single fastener capacity. In fact, numerical simulations here provided have shown that the racking capacity of glubam lightweight shear walls can be larger than those made of timber, despite the smaller size of their framing elements. This is because the capacity of the fasteners here considered is higher for glubam walls than for timber ones, thereby emphasizing the fact that such a design parameter dictates the overall capacity of the wall when it is fully exploited.

Moreover, the cross-section size of the framing elements is important for determining the racking capacity for both types of walls. It seems, however, that the racking capacity of glubam shear walls is much more sensitive to this design parameter.

Finally, it is remarked that the size of the framing elements is an important design parameter to define the overall wall ductility, too. The use of smaller cross-sections in glubam walls, as compared to timber walls, reduce the amount of plastic deformations in the fasteners of the former and thus the corresponding ductility. 


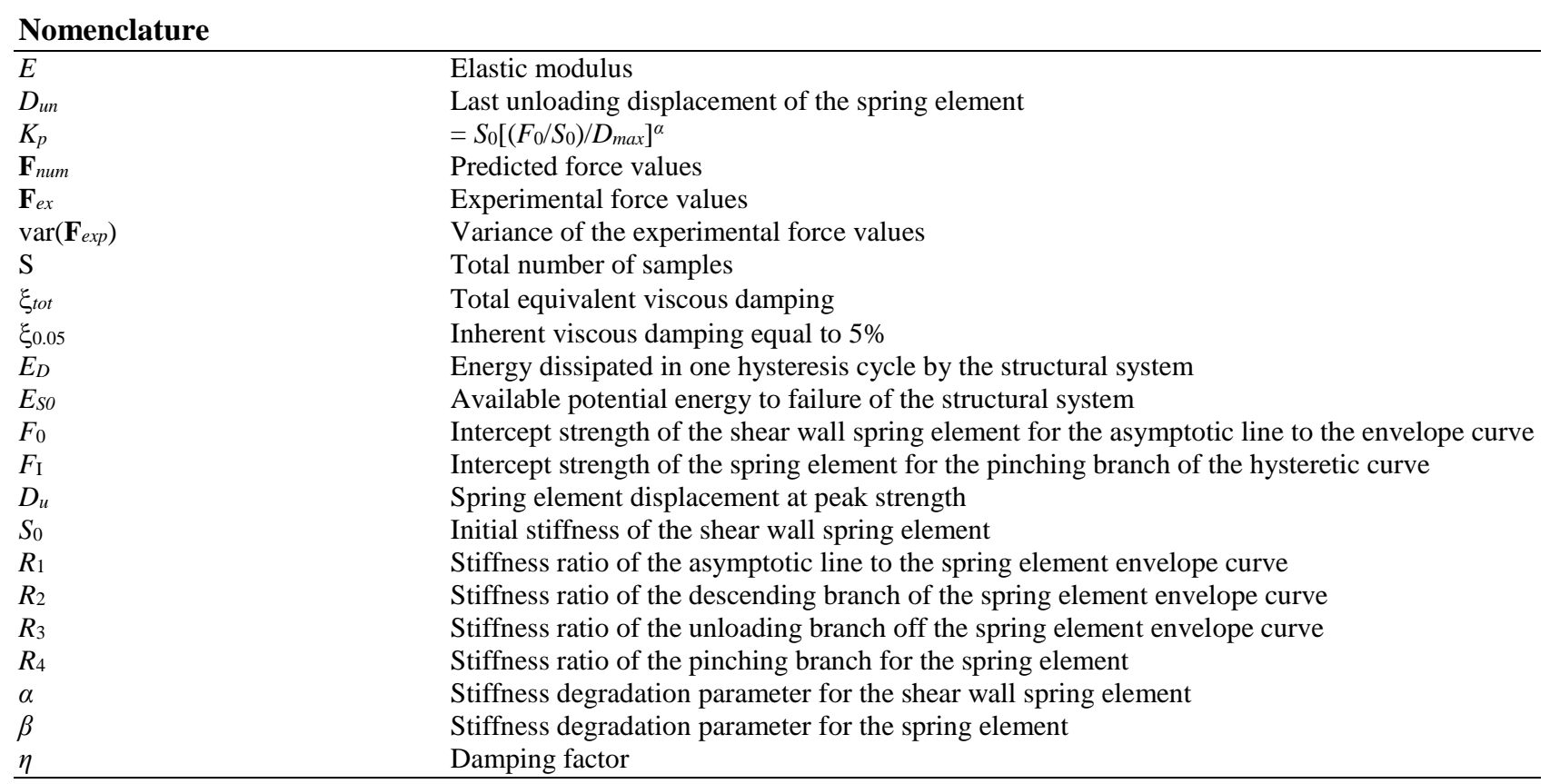

\section{Acknowledgement}

The authors would like to thank R. Wang., S. Q. Wei, Z. Li and Y. Xiao for having shared the data of the experimental tests reported in (Wang et al., 2019).

\section{Funding Information}

This work has been partially supported by the Zhejiang University/University of Illinois at UrbanaChampaign Institute.

\section{Author's Contributions}

Giorgia Di Gangi: Conceptualization, methodology, programming, software, numerical analyses, writing original draft preparation.

Giuseppe Quaranta and Cristoforo Demartino: Methodology, programming, writing - review and editing.

\section{Ethics}

The Authors declare that this article is original and contains unpublished material. The corresponding Author confirms that all of the other Authors have read and approved the manuscript and no ethical issues are involved.

\section{References}

Ashby, M.F., 1992. Materials Selection in Mechanical Design. 1st Edn., Butterworth-Heinemann, ISBN-10: 0750627271, pp: 311.

BSI, 2016. EN 338-Structural timber strength classes. British Standards Institution.
Chopra, A.K., 1995. Dynamics of Structures: Theory and Applications to Earthquake Engineering. 4th Edn., Pearson Education Limited, ISBN-10: 0273774247, pp: 984.

Di Gangi, G., C. Demartino, G. Quaranta and G. Monti, 2020. Dissipation in sheathing-to-framing connections of light-frame timber shear walls under seismic loads. Eng. Structures, 208: 110246-110246. DOI: $10.1016 /$ j.engstruct.2020.110246

Dolan, J.D., 1989. The dynamic response of timber shear walls. PhD Thesis, University of British Columbia.

CEN, 2004a European Committee for Standardization. Eurocode 8: Design of Structures for Earthquake Resistance. Part 1: General Rules, Seismic Actions and Rules for Buildings, European Standard, EN 1998-1.

CEN, 2004b European Committee for Standardization Eurocode 5: Design of Timber Structures. Part 1-2: General - Structural fire design, European Standard, EN 1995-1-2.

Folz, B. and A. Filiatrault, 2001. Cyclic analysis of wood shear walls. J. Structural Eng., 127: 433-441. DOI: 10.1061/(ASCE)0733-9445(2001)127:4(433)

Foschi, R.O., 1974. Load-slip characteristics of nails. Wood Sci., 7: 69-76.

Gattesco, N. and I. Boem, 2016. Stress distribution among sheathing-to-frame nails of timber shear walls related to different base connections: Experimental tests and numerical modelling. Constr. Buil. Mater., 122: 149-162. DOI: 10.1016/j.conbuildmat.2016.06.079

Ghavami, K., 2008. Bamboo: Low cost and energy saving construction material. Proceedings of the 1st International Conference on modern bamboo structures, Oct. 28-30, Changsha, China, pp: 5-21. DOI: $10.1201 / 9780203888926 . c h 2$ 
Gupta, A.K. and G.P. Kuo, 1985. Behavior of wood-framed shear walls. J. Structural Eng., 111: 1722-1733. DOI: 10.1061/(ASCE)0733-9445(1985)111:8(1722)

Gupta, A.K. and G.P. Kuo, 1987. Wood-framed shear walls with uplifting. J. Structural Eng., 113: 241-259. DOI: 10.1061/(ASCE)0733-9445(1987)113:2(241)

Gutkowski, R.M. and A.L. Castillo, 1988. Single-and double-sheathed wood shear wall study. J. Structural Eng., 114: 1268-1284. DOI: 10.1061/(ASCE)0733-9445(1988)114:6(1268)

He, M., H. Magnusson, F. Lam and H.G.L. Prion, 1999. Cyclic performance of perforated wood shear walls with oversize OSB panels. J. Structural Eng., 125: 10-18.

DOI: 10.1061/(ASCE)0733-9445(1999)125:1(10)

Jayamon, J., F. Charney, F. Flores and P. Line, 2016. Influence of wall load-displacement shape on seismic performance of wood-frame shear wall structures. Proceedings of the World Conference on Timber Engineering, (CTE' 16), Vienna, Austria.

Jayanetti, D.L. and P.R. Follett, 2008. Bamboo in construction. Proceedings of the 1st International Conference on modern bamboo structures, Oct. 28-30, Changsha, China, pp: 23-32.

DOI: $10.1201 / 9780203888926 . c h 3$

Källsner, B. and U.A. Girhammar, 2009. Analysis of fully anchored light-frame timber shear wallsElastic model. Mater. Structures, 42: 301-320. DOI: $10.1617 / \mathrm{s} 11527-008-9463-\mathrm{X}$

Kibert, C.J., 2016. Sustainable Construction: Green Building Design and Delivery. 14th Edn., John Wiley and Sons, ISBN-10: 1119055172 , pp: 608.

Li, Z., 2015. Reliability based design of light-weight wood-frame shear walls with ply-bamboo sheathing panels. PhD Thesis, Sapienza University of Rome.

Li, Z., Y. Xiao, B. Shan, L. Li and R. Wang, 2012. Monotonic and cyclic tests of round bamboo shear walls. Key Eng. Mater., 517: 135-140.

DOI: 10.4028/www.scientific.net/KEM.517.135

Ma, F., C.H. Ng and N. Ajavakom, 2006. On system identification and response prediction of degrading structures. Structural Control Health Monit., 13: 347-364. DOI: 10.1002/stc. 122

Mahdavi, M., P.L. Clouston and S.R. Arwade, 2010. Development of laminated bamboo lumber: Review of processing, performance and economical considerations. J. Mater. Civil Eng., 23: 1036-1042. DOI: 10.1061/(ASCE)MT.1943-5533.0000253

McKenna, F. and G. Fenves, 2001. The OpenSees Command Language Manual: version 1.2. Pacific Earthquake Engineering Center, University of California, Berkeley, USA.

Minke, G., 2016. Building with Bamboo: Design and Technology of a Sustainable Architecture. 2nd Edn., Birkhauser, ISBN-10: 303561024X, pp: 159.
Moghadam, S.M.J.F., 2017. The most complete applied reference of OpenSees.

Paudel, S.K., 2008. Engineered bamboo as a building material. Proceedings of the 1st International Conference on Modern Bamboo Structures, Oct. 28-30, Changsha, China, pp: 33-40. DOI: $10.1201 / 9780203888926 . c h 4$

Quaranta, G., G. Monti and G.C. Marano, 2010. Parameters identification of Van der Pol-Duffing oscillators via particle swarm optimization and differential evolution. Mech. Syst. Signal Proc., 24: 2076-2095. DOI: 10.1016/j.ymssp.2010.04.006

Quaranta, G., W. Lacarbonara and S.F. Masri, 2020. A review on computational intelligence for identification of nonlinear dynamical systems. Nonlinear Dynam., 99: 1709-1761. DOI: $10.1007 / \mathrm{s} 11071-019-05430-7$

Tuomi, R.L. and W.J. McCutcheon, 1978. Racking strength of light-frame nailed walls. J. Structural Divis., 104: 1131-1140.

USC, 2005. Energy policy act of. United States Congress

Wang, J.S., C. Demartino, Y. Xiao and Y.Y. Li, 2018. Thermal insulation performance of bamboo and wood-based shear walls in light-frame buildings. Energy Buil., 168: 167-79.

DOI: 10.1016/j.enbuild.2018.03.017

Wang, R., S.Q. Wei, Z. Li and Y. Xiao, 2019. Performance of connection system used in lightweight glubam shear wall. Constr. Buil. Mater., 206: 419-431.

DOI: 10.1016/j.conbuildmat.2019.02.081

Wang, R., Y. Xiao and Z. Li, 2017. Lateral loading performance of lightweight Glubam shear walls. J. Structural Eng., 143: 04017020-04017020. DOI: 10.1061/(ASCE)ST.1943-541X.0001751

Wegst, U.G.K., H.R. Shercliff and M.F. Ashby, 1993. The structure and properties of bamboo as an engineering material. University of Cambridge, UK.

White, M.W. and J.D. Dolan, 1995. Nonlinear shear-wall analysis. J. Structural Eng., 121: 1629-1635. DOI: 10.1061/(ASCE)0733-9445(1995)121:11(1629)

Xiao, Y., R.Z. Yang and B. Shan, 2013. Production, environmental impact and mechanical properties of glubam. Constr. Buil. Mater., 44: 765-73. DOI: 10.1016/j.conbuildmat.2013.03.087

Xiao, Y., Z. Li and R. Wang, 2014a. Lateral loading behaviors of lightweight wood-frame shear walls with ply-bamboo sheathing panels. J. Structural Eng., 141: B4014004-B4014004.

DOI: 10.1061/(ASCE)ST.1943-541X.0001033

Xiao, Y., B. Shan, R.Z. Yang, Z. Li and J. Chen, 2014b. Glue laminated bamboo (glubam) for structural applications. Mater. Joints Timber Structures. 